\title{
Long-time visual functional results of cataract surgery on low vision patients
}

\author{
Eva I Mönestam \\ Britta M Lundqvist \\ Åsa C Jonsson
}

Department of Clinical Sciences/ Ophthalmology, Umeå University, Umeå, Sweden
Correspondence: Eva Mönestam

Department of Clinical Sciences/

Ophthalmology, Umeå University, S-90185

Umeå, Sweden

Tel +46 907851342

Fax $+4690 \quad 145997$

Email eva.monestam@vll.se
Background/aims: To assess longitudinal 5-year results of cataract surgery on low vision patients.

Methods: In this prospective, long-time, observational case-series, we report the outcome regarding the subjective visual function $(\mathrm{n}=35)$ assessed by a visual function questionnaire (VF-14) and the visual acuity $(n=30)$ of surviving low vision patients 5 years after surgery. We compare with data recorded on the same patients before surgery and 4 months postoperatively.

Results: Five years after surgery, 57\% had unchanged or better VF-14 score compared with preoperatively, and 37\% compared with postoperatively. Maculopathy patients had a significantly larger deterioration 5 years after surgery compared with postoperatively (40.2 versus $51.7, \mathrm{p}=0.004)$, but for the glaucoma patients there was no significant change (52.6 versus 53.1). There were no significant associations between age of the patient and change in VF-14 score or change in visual acuity 5 years after surgery, neither compared with before surgery nor postoperatively.

Conclusion: Results suggest a favorable functional outcome 5 years after cataract surgery on most low-vision patients. Glaucoma patients have a more stable outcome than patients with macular degeneration. The severity of the disease-process for each individual patient might be the most important factor affecting the long-time results.

Keywords: low vision, cataract surgery outcome, long-time results

\section{Introduction}

Cataract is known to be the most common secondary diagnosis in low vision patients and has been estimated to be a concurrent cause in $75 \%$ of visually impaired people aged 70+ (Laatikainen and Hirvelä 1995; Elliott et al 1997).

Previous studies have shown that a large proportion of low vision patients with significant cataract benefit from cataract extraction (Mönestam and Wachtmeister 1997; Lundström et al 2002; Armbrecht et al 2003).

Even though most low vision patients are old with a limited life span, it is important from a public health perspective to assess long-time results as low vision is responsible for a high proportion of social service needs, contributes to the loss of independence in older age, and increases mortality (Wang et al 1999, 2001; Buch et al 2001). Impaired vision has a large psychological impact on peoples' lives, and it is important to establish the long-time results of cataract surgery to improve the counseling of patients with cataract and concurrent eye diseases (Carabellese et al 1993; Williams et al 1998).

The purpose of the study was to determine the longitudinal results of cataract surgery on the self-estimated ability to perform specific visual tasks and the relation to visual acuity in low vision patients.

\section{Patients and methods}

This prospective study included all patients attending the Low Vision Clinic, at Norrlands University Hospital in Umeå, Sweden, who were scheduled for cataract surgery 
between June 1st 1997 and May 31st 1998. Patients who underwent cataract surgery, ie, small-incision phacoemulsification, during the same time-period and were admitted to the Low Vision Clinic after surgery were also included (20/81; $25 \%$ ). These patients were found to have a non-treatable ocular disease, filling the criteria of low vision. In our area a functionally disabling cataract of the fellow eye is extracted before the patient is admitted to the Low Vision Clinic (LV). These patients were slightly but not significantly younger than those who were already in The LV clinic. There was no significant difference in diagnosis (except that no new patient had retinitis pigmentosa $[\mathrm{RP}]$ ) and there was no significant gender difference. All patients who had low vision before cataract surgery still had low vision after surgery. Prescribed low vision aids are free in Sweden, for that reason all patients attended the LV clinic postoperatively.

Low vision was defined in consistence with World Health Organization (WHO) criteria, as a binocular visual acuity of $0.3(20 / 66)$ or worse if the peripheral visual fields were normal. If advanced losses of the visual fields were present, a visual acuity less than $0.5(20 / 40)$ in the better eye was allowed (WHO 2001). Advanced visual field losses were defined as a remaining binocular visual field of less area than one normal visual field.

Eighty-one low vision patients were enrolled in 1997-98. Five years later 39 had deceased (48\%), 6 could not participate because of dementia (7\%), and 1 patient (1\%) could not be located. Thirty-five patients participated with the questionnaire, ie, $97 \%$ of the eligible sample (35/36). In addition to the questionnaire, 30 patients also underwent an eye examination, $71 \%$ of the survivors (30/42). The major reason for not participating with the eye examination was trouble/unwillingness to travel to the eye clinic, either because of illness or long distance.

All patients were part of a larger population-based prospective study of cataract surgery outcome described in detail in earlier publications (Mönestam et al 2005; Lundqvist and Mönestam 2006). The study followed the tenets of the declaration of Helsinki. The Medical Ethics Committee of Umeå University, Sweden, approved this study, and all patients gave informed consent.

\section{Pre- and postoperative data}

The following data were recorded; age, sex, first or second eye surgery, presenting and best corrected monocular visual acuity (BCVA), refraction of both eyes before surgery and postoperatively, type of surgery, complications, and diagnosis of the ocular comorbidity. No serious peri- or postoperative complications were noted. Only BCVA data are reported, as presenting visual acuity postoperatively and 5 years after surgery were very similar.

Before surgery the patients answered a questionnaire regarding their subjective assessment of visual function and ability to perform visually demanding tasks (VF-14) (Steinberg et al 1994a, 1994b; Cassard et al 1995). All subjects were given the same instructions and were asked to answer the questionnaire using both eyes open and any habitually used spectacles and/or low vision aids. If the patient was unable to read the questionnaire, it was administered in a standardized manner by interview, or over the telephone for those patients unable to visit the clinic $(n=5)$.

Approximately 4-5 months postoperatively it was checked that glasses and necessary low-vision aids had been prescribed and trained. A third questionnaire similar to the first and second was administered to the patients.

Five years after surgery it was checked which patients were still alive. All survivors were asked to participate with the same questionnaire, and a new eye examination. The examination was performed in the same manner as in 1997-98.

\section{Definitions of diagnoses}

Only one diagnosis was chosen as the primary cause of low vision, as it was in most cases one disorder. When multiple disorders were present, the disease with the most clinically significant and irreversible influence was chosen as the primary cause.

Each subject was assigned to a primary diagnostic category: (1): The maculopathy patients (M-patients), ( $n=55 / 81 ; 68 \%$ ). The macular function was depressed and the peripheral visual fields were normal. Age-related macular degeneration (ARM) (49/81; 60\%), diabetic maculopathy (2/81; $2 \%)$, myopic maculopathy $(4 / 81 ; 5 \%)$. Five years after surgery the M-group consisted of 22 patients, 20 with ARM, 1 with diabetic maculopathy, and 1 with myopic maculopathy. (2): The glaucoma patients (G-patients), $(\mathrm{n}=23 / 81 ; 28 \%)$. These patients had advanced visual field defects caused by glaucoma in 22 cases, and tumor of the hypophysis in 1 case. The visual field losses were together larger than the size of one normal visual field. Five years after surgery, 11 patients remained, 10 with glaucoma and 1 with tumor-related extensive visual field defects. (3): The retinitis pigmentosa patients (RP-patients) $(n=3 / 81 ; 4 \%)$. Five years after surgery, 2 patients remained and both had signs of maculopathy. 


\section{Statistical methods}

Patients with failure to read any letters on the ETDRS-chart were tested using hand movements (HM), and light perception $(\mathrm{P})$, and scored as outlined in earlier publications (Mönestam and Wachtmeister 1999; Mönestam and Lundqvist 2006). Change of VA was calculated as logMAR acuity (logVA) before surgery subtracted by $\log$ VA postoperatively or $\log$ VA postoperatively subtracted by $\log$ VA 5 years after surgery, respectively. For example: VA postoperatively $=\log$ MAR 0.8 (Snellen 20/125) and VA 5 years after surgery $=\log$ MAR 1 (Snellen 20/200), results in a deterioration of $0.8-1=-0.2$ $\log$ MAR units.

Two-tailed t-tests were used to assess differences in age and VF-14 score. Mann-Whitney U-tests were used to compare changes of VA postoperatively and 5 years after surgery. The two by two frequency tables were analyzed using Yates' corrected chi-square tests or Fischers' exact tests.

To calculate correlations Spearman's rank correlation $\left(\mathrm{r}_{\mathrm{s}}\right)$ corrected for ties was used. Partial correlations statistics $\left(r_{p}\right)$ were performed to explore the correlations between the 5 year VA-results, VF-14 score, type of diagnosis, age, and gender.

The reading ability score was calculated by adding the scores of the 3 questions concerning subjective reading ability from the VF-14 questionnaire, ie, difficulties to read small print, newsprint and headlines, theoretical response-range $0-12$, with 0 meaning no ability to read, not even large print as headlines, and 12 meaning no perceived difficulties with reading also small print) (Steinberg et al 1994a). Wilcoxon signed ranks tests were used to analyze the reading ability score.

The data were analyzed using the SSPS software 12.0 (SPSS for Windows; SPSS, Chicago IL).

\section{Results}

\section{Demographic characteristics, VA, and VF-I 4 score.}

The demographic characteristics, VA-distribution, and subjective visual function (VF-14 total score), before surgery, postoperatively, and 5 years after surgery of the 3 patient groups, are shown in Table 1.

The RP-patients were significantly younger than the M- and G-patients $(p<0.000)$ The results of the RP-patients are shown in Table 1, but no further statistical calculations have been made because of the small size of this patient group $(\mathrm{n}=2-3)$. Postoperatively there was a highly significant improvement of the VF-14 and the VA of the operated eye, as well as for the better-seeing eye for M- and G-patients (Table 1).
Five years after surgery there was a statistically significant decrease in VA of the operated eye in both M- and G- patients ( $p=0.026$ and 0.003 , respectively, Table 1). Regarding the VA of the better-seeing eye there was no significant change. Most patients had had surgery on their fellow eyes during the 5 -year period (78\%). Three patients had undergone YAG laser capsulotomy before the 5-year examination. No additional patient had posterior capsular opacification at the time of the examination of such degree that YAG-laser was indicated.

The M-group had a significantly worse VF-14 score 5 years after surgery compared with postoperatively (40.2 versus 51.7, $\mathrm{p}=0.004)$. The VF-14 score of the G-group did not change significantly (52.6 versus 53.1 , Table 1$)$.

\section{Longitudinal change in VA andVF-I 4 score.}

The change in VA, 5 years after surgery, regarding the operated eye and the better-seeing eye was generally scattered, with some patients having an excellent outcome with little loss, and others having a large deterioration (Table 2).

There were no significant partial correlations in 5-year VA results in relation to age, gender and diagnosis of the patient. The associations between age and change in VA of the operated eye and better-seeing eye were $r_{S}=-0.20$ $(p=0.29)$ and $r_{S}=-0.04(p=0.84)$, respectively.

In Table 3 the distribution of change in VF-14 score, 5 years after surgery versus before surgery, is shown. This analysis focus on the change in visual function 5 years after surgery, taking account of the surgical procedure, and also any second eye surgery during the follow up period. Fifty-seven percent (20/35) of the total patient group had an improved or better VF-14 score 5 years later, compared with before surgery.

The VF-14 score 5 years after surgery was also compared with the VF-14 score postoperatively, and 37\% (13/35) of the patients were unchanged or better (Table 3 ). There were no statistically significant associations between age of the patient and change in VF-14 score 5 years after surgery either compared with VF-14 before surgery or postoperatively (data not shown).

\section{Reading ability}

The median subjective reading ability score before surgery, postoperatively, and 5 years after surgery for the patient groups are shown in Table 4 . Five years after surgery, 8 patients $(8 / 35 ; 23 \%)$ had improved their reading score, $10(10 / 35$; $29 \%)$ were unchanged and $17(17 / 35 ; 49 \%)$ had worse reading score, compared with postoperatively almost 5 years earlier. The two RP-patients had had overall good subjective reading 
Table I Mean age, age-range, percentage of males, percentage of first eye surgery, VA-distribution, and subjective visual function (VF-I4 total score), before surgery, postoperatively and 5 years after surgery

\begin{tabular}{|c|c|c|c|c|c|}
\hline & \multicolumn{5}{|l|}{ Diagnosis } \\
\hline & All patients & M-patients & G-patients & RP-patients & p-value* \\
\hline No of patients & 81 & 55 & 23 & 3 & \\
\hline Mean age at surgery (years) & 80.1 & 81.5 & 81.0 & 47.3 & 0.8 \\
\hline Range (years) & $30-96$ & $62-96$ & $43-93$ & $30-74$ & \\
\hline Males (\%) & 31 & 31 & 35 & 0 & 0.94 \\
\hline Surgery on first eye (\%) & 72 & 69 & 77 & 67 & 0.59 \\
\hline \multicolumn{6}{|l|}{ VA operated eye before surgery } \\
\hline $20 / 90$ or better & 3 & 0 & 2 & 1 & 0.42 \\
\hline $20 / 200-20 / 100$ & 10 & 8 & 2 & 0 & \\
\hline CF-20/250 & 54 & 41 & 11 & 2 & \\
\hline$P-H M$ & 14 & 6 & 8 & 0 & \\
\hline \multicolumn{6}{|l|}{ VA better eye before surgery } \\
\hline $20 / 90$ or better & 12 & 7 & 4 & 1 & 0.6 \\
\hline $20 / 200-20 / 100$ & 36 & 26 & 10 & 0 & \\
\hline CF-20/250 & 31 & 20 & 9 & 2 & \\
\hline $\mathrm{P}-\mathrm{HM}$ & 2 & 2 & 0 & 0 & \\
\hline \multicolumn{6}{|l|}{ VA operated eye postoperative } \\
\hline $20 / 90$ or better & 23 & 14 & 8 & 1 & 0.086 \\
\hline $20 / 200-20 / 100$ & 36 & 30 & 5 & 1 & \\
\hline CF-20/250 & 15 & 10 & 5 & 1 & \\
\hline $\mathrm{P}-\mathrm{HM}$ & 6 & 1 & 5 & 0 & \\
\hline \multicolumn{6}{|l|}{ VA better eye postoperatively } \\
\hline $20 / 90$ or better & 30 & 19 & 10 & 1 & 0.67 \\
\hline $20 / 200-20 / 100$ & 37 & 28 & 7 & 2 & \\
\hline CF-20/250 & 14 & 8 & 6 & 0 & \\
\hline$P-H M$ & 0 & 0 & 0 & 0 & \\
\hline Mean improvement VA operated eye, logMAR units & $0.62(0.7 I)$ & $0.71(0.67)$ & $0.49(0.82)$ & $0.03(0.35)$ & 0.28 \\
\hline$(S D), p$-value ${ }^{\dagger}$ & $<0.000$ & $<0.000$ & 0.0093 & & \\
\hline Mean improvement VA better eye, & $0.35(0.60)$ & $0.38(0.62)$ & $0.28(0.58)$ & $0.05(0.09)$ & 0.47 \\
\hline $\log M A R$ units (SD), $p$-value ${ }^{\dagger}$ & $<0.000$ & $<0.000$ & 0.047 & & \\
\hline VF-I 4 before surgery $(n=8 I)$ mean $(S D)$ & $40.0(26.7)$ & $30.3(25.7)$ & $35.0(27.5)$ & $66.9(17.8)$ & 0.47 \\
\hline VF-I4 postoperatively $(n=8 I)$ & $48.8(30.2)$ & $47.4(28.6)$ & $49.2(34.9)$ & $70.4(16.7)$ & 0.81 \\
\hline mean $(S D), p_{-}$-value ${ }^{\dagger}$ & $<0.000$ & $<0.000$ & 0.024 & & \\
\hline \multicolumn{6}{|l|}{ Five-year data } \\
\hline No of patients with 5-yearVF-14 data & 35 & 22 & 11 & 2 & \\
\hline No with 5-yearVA \&VF-I4 data & 30 & 19 & 10 & I & \\
\hline Mean age 5 years after surgery, & 81.1 & 84.4 & 82.3 & 39 & 0.61 \\
\hline years $(S D)$ & $(13.5)$ & $(6.1)$ & $(\mid 2.5)$ & $(5,7)$ & \\
\hline Operated on both eyes after 5 years, $\%$. & 78 & 77 & $88 \#$ & 50 & 0.64 \\
\hline \multicolumn{6}{|l|}{ VA operated eye before surgery $(n=30)$} \\
\hline $20 / 90$ or better & I & 0 & 1 & 0 & 0.76 \\
\hline $20 / 200-20 / 100$ & 7 & 5 & 2 & 0 & \\
\hline CF-20/250 & 17 & 12 & 4 & 1 & \\
\hline $\mathrm{P}-\mathrm{HM}$ & 5 & 2 & 3 & 0 & \\
\hline \multicolumn{6}{|l|}{ VA operated eye postop $(n=30)$} \\
\hline $20 / 90$ or better & 8 & 3 & 5 & 0 & 0.39 \\
\hline $20 / 200-20 / 100$ & 16 & 12 & 3 & 1 & \\
\hline CF-20/250 & 5 & 4 & 1 & 0 & \\
\hline $\mathrm{P}-\mathrm{HM}$ & I & 0 & 1 & 0 & \\
\hline \multicolumn{6}{|l|}{ VA operated eye 5 years after surgery $(n=30)$} \\
\hline $20 / 90$ or better & 2 & 0 & 1 & 1 & 0.51 \\
\hline $20 / 200-20 / 100$ & II & 8 & 3 & 0 & \\
\hline CF-20/250 & 18 & 11 & 2 & 0 & \\
\hline $\mathrm{P}-\mathrm{HM}$ & 4 & 0 & 4 & 0 & \\
\hline p-value ${ }^{\S}$ & $<0.000$ & 0.026 & 0.003 & & \\
\hline
\end{tabular}

(Continued) 
Table I Continued

\begin{tabular}{|c|c|c|c|c|c|}
\hline & \multicolumn{5}{|l|}{ Diagnosis } \\
\hline & All patients & M-patients & G-patients & RP-patients & p-value* \\
\hline \multicolumn{6}{|l|}{ VA better eye bef surg $(n=30)$} \\
\hline $20 / 90$ or better & 3 & 2 & I & 0 & 0.32 \\
\hline $20 / 200-20 / 100$ & 17 & 11 & 5 & 1 & \\
\hline CF-20/250 & 9 & 5 & 4 & 0 & \\
\hline $\mathrm{P}-\mathrm{HM}$ & I & I & 0 & 0 & \\
\hline \multicolumn{6}{|l|}{ VA better eye postop $(n=30)$} \\
\hline $20 / 90$ or better & 10 & 5 & 5 & 0 & 0.92 \\
\hline $20 / 200-20 / 100$ & 16 & 12 & 3 & I & \\
\hline CF-20/250 & 4 & 2 & 2 & 0 & \\
\hline$P-H M$ & 0 & 0 & 0 & 0 & \\
\hline \multicolumn{6}{|l|}{ VA better eye 5 years after surg $(n=30)$} \\
\hline $20 / 90$ or better & 10 & 5 & 5 & 0 & 0.21 \\
\hline $20 / 200-20 / 100$ & 7 & 5 & 2 & 0 & \\
\hline CF-20/250 & 12 & 9 & 2 & I & \\
\hline $\mathrm{P}-\mathrm{HM}$ & I & 0 & I & 0 & \\
\hline $\mathrm{P}$-value ${ }^{\S}$ & 0.23 & 0.18 & 0.8 & & \\
\hline Mean VF- 14 before surg $(n=35)$ & $37.4(27.3)$ & $35.4(28.6)$ & $34.2(21.9)$ & $76.7(8.3)$ & 0.99 \\
\hline Mean VF-I4 postoperat $(n=35)$ & $53.7(26.2)$ & $51.7(24.9)$ & $53.1(29.8)$ & $79.1(10.3)$ & 0.86 \\
\hline Mean VF-I 45 years after surg $(n=35)$ & $46.6(31.7)$ & $40.2(27.7)$ & $52.6(37.6)$ & $83.0(8.0)$ & 0.34 \\
\hline $\mathrm{p}$-value s $^{\S}$ & 0.026 & 0.004 & 0.93 & & \\
\hline
\end{tabular}

Notes: ${ }^{*} \mathrm{p}$-values refer to M-patients versus G-patients (t- tests and Mann-Whitney U-tests); ${ }^{\dagger} \mathrm{p}$-values refer to change postoperatively versus before surgery, (t- tests and Mann-Whitney U-tests); ${ }^{\S}$-values refer to change 5 -years after surgery versus postoperatively. (t- tests and Mann-Whitney U-tests); \#Two patients with no light perception on their fellow eyes were excluded; Values in boldface are statistically significant $(p<0.05)$.

Abbreviations: M-patients, maculopathy patients; G-patients, glaucoma patients; RP-patients, retinitis pigmentosa patients; LogMAR, logarithm of the minimum angle of resolution; VA, visual acuity; VF-I4, visual function questionnaire; CF, counting fingers; HM, hand movements; P, light perception.

ability with little change 5 years after surgery. M-patients compared with G-patients had a worse outcome when reading ability was assessed with a significant decrease in reading score 5 years postoperatively $(p=0.045$, Table 4$)$.

The reading score 5 years after surgery showed a strong statistically significant correlation with the VA of the better seeing eye, both for M-patients as well as G- patients $\left(r_{\mathrm{S}}=0.76\right.$ and $\mathrm{r}_{\mathrm{S}}=0.9$, respectively, p-values 0.000$)$.

\section{Discussion}

The present study provides an evaluation of long-time outcome in a geographically defined cohort of low-vision

Table 2 Distribution of change in VA for the operated eye and the better-seeing eye 5 years after surgery versus postoperatively, for the Maculopathy patients (M-patients), Glaucoma patients (G-patients), and the retinitis pigmentosa patients (RP-patients)

\begin{tabular}{|c|c|c|c|c|c|}
\hline $\begin{array}{l}\text { Change in VA operated eye } \\
5 \text { years after surgery, no (\%) }\end{array}$ & $\begin{array}{l}\text { All patients } \\
(n=30)\end{array}$ & $\begin{array}{l}\text { M-patients } \\
(n=19)\end{array}$ & $\begin{array}{l}\text { G-patients } \\
(n=10)\end{array}$ & $\begin{array}{l}\text { RP-patients } \\
(n=1)\end{array}$ & p-value \\
\hline Unchanged or better, no (\%) & $7(23)$ & $7(37)$ & 0 & 0 & \\
\hline $0.0 \mathrm{I}-0,3$ decline logMAR units & $3(10)$ & $\mathrm{I}(5)$ & $2(20)$ & 0 & \\
\hline $0.3 \mathrm{I}-0.5$ decline logMAR units & $9(30)$ & $4(2 I)$ & $5(50)$ & 0 & \\
\hline $0.5 \mathrm{I}-0.7$ decline logMAR units & $7(23)$ & $6(32)$ & 0 & 1 & \\
\hline$>0.7$ decline logMAR units & $4(14)$ & $\mathrm{I}(5)$ & $3(30)$ & 0 & $\mathrm{P}=0.33^{*}$ \\
\hline \multicolumn{6}{|l|}{ Change in VA better seeing eye } \\
\hline Unchanged or better, no (\%) & $12(40)$ & $8(42)$ & $4(40)$ & 0 & \\
\hline $0.0 \mathrm{I}-0,3$ decline logMAR units & $9(30)$ & $4(21)$ & $5(50)$ & 0 & \\
\hline $0.3 \mathrm{I}-0.5$ decline $\log M A R$ units & $5(17)$ & $4(21)$ & 0 & I & \\
\hline $0.5 \mathrm{I}-0.7$ decline logMAR units & $3(10)$ & $3(16)$ & 0 & 0 & \\
\hline$>0.7$ decline logMAR units & I (3) & 0 & $\mathrm{I}(10)$ & 0 & $\mathrm{P}=0.40^{*}$ \\
\hline
\end{tabular}

Notes: *The p-value refers to the difference between M- and G-group (Mann-Whitney U-test).

Abbreviations: VA, best corrected visual acuity; logMAR, logarithm of the minimum angle of resolution. 
Table 3 Distribution of change in VF-I4, 5 years after surgery versus before surgery and postoperatively, respectively

\begin{tabular}{|c|c|c|c|c|c|}
\hline $\begin{array}{l}\text { Change in VF- I } 4 \text { score } 5 \text { years after } \\
\text { surgery versus before surgery, no (\%) }\end{array}$ & $\begin{array}{l}\text { All patients } \\
(n=35)\end{array}$ & $\begin{array}{l}\text { M-patients } \\
(\mathrm{n}=22)\end{array}$ & $\begin{array}{l}\text { G-patients } \\
(n=I I)\end{array}$ & $\begin{array}{l}\text { RP-patients } \\
(n=2)\end{array}$ & p-value \\
\hline Unchanged or better; no (\%) & $20(57)$ & II (50) & $8(73)$ & I (50) & \\
\hline Worsening of VF-14 score $<10$ & $8(23)$ & $6(27)$ & I (9) & I (50) & \\
\hline Worsening of VF-14 score $10-20$ & $5(14)$ & $3(14)$ & $2(18)$ & 0 & \\
\hline Worsening of VF-14 score $>20$ & $2(6)$ & $2(9)$ & 0 & 0 & $0.30 *$ \\
\hline \multicolumn{6}{|l|}{$\begin{array}{l}\text { Change in VF-I } 4 \text { score } 5 \text { years after } \\
\text { surgery versus postoperatively, no (\%) }\end{array}$} \\
\hline VF-I 4 unchanged or better & $13(37)$ & $5(23)$ & $6(55)$ & $2(100)$ & \\
\hline Worsening of VF-14 score $<10$ & $7(20)$ & $6(27)$ & I (9) & & \\
\hline Worsening of VF-14 score $10-20$ & $7(20)$ & $6(27)$ & I (9) & & \\
\hline Worsening of VF-14 score $>20$ & $8(23)$ & $5(23)$ & $3(27)$ & & $0.36^{*}$ \\
\hline
\end{tabular}

Notes: *The p-values refer to the difference between M- and G-group (Mann-Whitney U-test).

Abbreviations: M-patients, maculopathy patients; G-patients, glaucoma patients; RP-patients, retinitis pigmentosa patients; VF-I4, visual function questionnaire total score.

patients who had cataract surgery. Our results suggest a favorable functional outcome for most low-vision patients, with $57 \%$ of the patients having unchanged or better VF-14 score compared with before surgery, and 37\% compared with postoperatively.

Glaucoma patients were found to have a more stable outcome with no significant change in VF-14 score (Table 1). The reason for this might be that the surgical procedure in itself generally lowers the intraocular pressure with approximately 1-3 mmHg, (Hayashi et al 2000, 2001; Mathalone et al 2005) and increased efficiency of modern pressurelowering eye drops.

There was one patient in the G-group with severely damaged visual function caused by a tumor of the hypophysis. The G-group was therefore analyzed after excluding this patient to ensure that the patient, with perhaps less risk for progressive disease than the glaucoma patients, did not "confound" the 5-year outcome. The results for the G-group did not change by excluding this patient.

It is not surprising that M-patients had a significantly worse 5-year outcome than G-patients when reading ability was assessed (Table 4).The disease process of AMD leads to loss of central vision which causes difficulties for those affected, particularly in reading and other near vision activities (Berdeaux et al 2005). Regarding the total low vision patient group the subjective reading ability was better 5 years after surgery compared with before surgery.

The diagnostic groups and the relations between them are similar to previous research (Hirvelä and Laatikainen 1995; Mönestam and Wachtmeister 1997). As expected macular degeneration was the leading cause of low vision.

In outcome studies the VA-result is often associated with the subjective visual function assessed by a questionnaire. In these cases it is essential to assess the VA of the patients' better-seeing eye, as the subjective visual function has been shown to depend more on the vision of the better eye than the worse eye (Steinberg et al 1994a; Mönestam and Wachtmeister 2004). In studies assessing cataract surgery outcome one must take account of the fact that the patient before surgery, in most instances, has two eyes with varying degree of cataract, or that the fellow eye might already has had surgery. In long-time studies of cataract surgery outcome it is common that the patients have second eye surgery during the follow-up period. It is important to take account of this when presenting the results.

Table 4 The median subjective reading ability score before surgery, postoperatively, and 5 years after surgery for the patient-groups

\begin{tabular}{lllll}
\hline $\begin{array}{l}\text { Median score } \\
\text { (interquartile range) }\end{array}$ & $\begin{array}{l}\text { All patients } \\
(\mathbf{n}=\mathbf{3 5 )}\end{array}$ & $\begin{array}{l}\text { M-group } \\
(\mathbf{n}=\mathbf{2 2})\end{array}$ & $\begin{array}{l}\text { G-group } \\
(\mathbf{n}=\mathbf{I I})\end{array}$ & $\begin{array}{l}\mathbf{R} \text {-group } \\
(\mathbf{n}=\mathbf{2})\end{array}$ \\
\hline Before surgery & $2(6)$ & $2(5.4)$ & $2(6)$ & $\mathrm{II}(2)$ \\
Postoperatively & $5(7)$ & $5(6.4)$ & $7(7)$ & $9.5(1)$ \\
5 years after surgery & $3(7)$ & $1(5.5)$ & $6(9)$ & $10(0)$ \\
P-value* & 0.14 & 0.045 & 0.83 & \\
\hline
\end{tabular}

Notes: *refers to change in reading score 5 years after surgery versus postoperatively (paired Wilcoxon signed rank test). Abbreviations: M-patients, maculopathy patients, G-patients; glaucoma patients; RP-patients, retinitis pigmentosa patients. 
Five years after surgery the VA of the operated eye had deteriorated significantly but the VAs of the patients' betterseeing eyes were not significantly worse (Table I).

VA of the operated eye was unchanged or better in 37\% of the M-patients (Table 2). The 5-year change in VA for the operated eye is generally variable with a proportion of patients with unchanged or only minor deterioration and others who have worsened substantially. There was no association between age, gender, diagnosis, and degree of deterioration which supports the assumption that the severity of the diseaseprocess for each individual patient might be the most important factor affecting the long-time results for the operated eye.

No general conclusions regarding the long-time outcome of RP-patients can be made because of the small patientgroup. The patients analyzed in this study had a favorable outcome. Long-time studies in this patient group are clearly warranted because these patients often have cataract surgery at a younger age and have a longer life-span post-surgery (Jackson et al 2001).

The strength of the study is that it is population-based and prospective, with few dropouts from causes other than death and dementia.

Limitations of the study are that the surviving patients are relatively few because the mean age of the patients was 80 years at the time of surgery. Studies assessing any longtime outcome, 5 years or more, of low vision patients will have a large percentage of dropouts, in consistence with common knowledge that increasing age is an independent predictor of low vision (Buch et al 2001).

The severity of macular degeneration was neither checked nor graded before surgery or postoperatively. Reported visual function has been found to be significantly associated with the clinical severity of age-related maculopathy (Mangione et al 1999). Our study patients were low vision patients as a result of their disease and had a substantial age-related macular degeneration before surgery.

Other objective dimensions of visual function such as contrast sensitivity, glare disability, etc. were not analyzed in this study. We focused on the most common test of visual function ie distance VA and correlated the findings to the subjective statements of the patients. It is possible that, for instance, contrast sensitivity testing would add information especially concerning the dissatisfied group.

\section{Disclosure}

Preliminary data were presented as a Poster presentation at the American Academy of Ophthalmology Annual Meeting, Las Vegas, Nevada, USA, November 12th 2006. Grants from the Crown Princess Margareta's Committee for the Blind (KMA), Stockholm, Sweden, Umeå University, Umeå, Sweden, and Västerbottens county council research funds, Umeå, Sweden, are greatly acknowledged. The authors report no conflicts of interest.

\section{References}

Armbrecht AM, Findlay C, Aspinall PA, et al. 2003. Cataract surgery in patients with age-related macular degeneration. One year outcomes. $J$ Cataract Refract Surg, 29:686-93.

Berdeaux GH, Nordmann J-P, Colin E, et al. 2005. Vision-related quality of life in patients suffering from age-related macular degeneration. Am J Ophthalmol, 139:271-9.

Buch H, Vinding T, Nielsen NV. 2001. Prevalence and causes of visual impairment according to World Health Organization and United States criteria in an aged urban Scandinavian population. Ophthalmology, 108:2347-57.

Buch H, Vinding T, la Cour M, et al. 2005. Age-related maculopathy: A risk indicator for poorer survival in women. The Copenhagen City Eye Study. Ophthalmology, 112:305-12.

Carabellese C, Appollonio I, Rozzini, et al. 1993. Sensory impairment and quality of life in a community elderly population. J Am Geriatric Soc, 41:401-7.

Cassard SD, Patrick DL, Damiano AM, et al. 1995. Reproducibility and responsiveness of the VF-14; an index of functional impairment in patients with cataracts. Arch Ophthalmol, 113:1508-13.

Elliott DB, Trucolo-Ilic M, Graham Strong J, et al. 1997. Demographic characteristics of the vision-disabled elderly. Invest Ophthalmol Vis Sci, 38:2566-75.

Hayashi K, Hayashi H, Nakao F, et al. 2000. Changes in anterior chamber angle width and depth after intraocular lens implantation in eyes with glaucoma. Ophthalmology, 107:698-703.

Hayashi K, Hayashi H, Nakao F, et al. 2001. Effect of cataract surgery on intraocular pressure control in glaucoma patients. J Cataract Refract Surg, 27:1779-86.

Hirvelä H, Laatikainen L. 1995. Visual acuity in a population aged 70 years or older; prevalence and causes of visual impairment. Acta Ophthalmol Scand, 73:99-104.

Jackson H, Garway-Heath D, Rosen P, et al. 2001. Outcome of cataract surgery in patients with retinitis pigmentosa. Br J Ophthalmol, 85:936-8.

Laatikainen L, Hirvelä H. 1995. Prevalence and visual consequences of macular changes in a population aged 70 years and older. Acta Ophthalmol Scand, 73:105-10.

Lundqvist B, Mönestam E. 2006. Longitudinal changes in subjective and objective visual function five years after cataract surgery. J Cataract Refract Surg, 32:1944-55.

Lundström M, Brege KG, Floren I, et al. 2002. Cataract surgery and quality of life in patients with age related macular degeneration. $\mathrm{Br} J$ Ophthalmol, 86:1330-35.

Mangione CM, Gutierrez PR, Lowe G, et al. 1999. Influence of age-related maculopathy on visual functioning and health-related quality of life. Am J Ophthalmol, 28:45-53.

Mathalone N, Hyams M, Neiman S, et al. 2005. Long-term intraocular pressure control after clear corneal phacoemulsification in glaucoma patients. J Cataract Refract Surg, 31:479-83.

Mönestam E, Wachtmeister L. 1997. The impact of cataract surgery on low vision patients - a population based study. Acta Ophthalmol Scand, 75:569-76.

Mönestam E, Wachtmeister L. 1999. Dissatisfaction with cataract surgery in relation to visual results in a population-based study in Sweden. $J$ Cataract Refract Surg, 25:1127-34.

Mönestam E, Wachtmeister L. 2004. Impact of cataract surgery on the visual ability of the very old. Am J Ophthalmol, 137:145-55. 
Mönestam E, Lundquist B, Wachtmeister L. 2005. Visual function and car driving: longitudinal results 5 years after cataract surgery in a population. Br J Ophthalmol, 89:459-63.

Mönestam E, Lundqvist B. 2006. Long-time results and associations between subjective visual difficulties with car driving and objective visual function 5 years after cataract surgery. J Cataract Refract Surg, 32:50-5.

Steinberg EP, Tielsch JM, Schein OD, et al. 1994a. The VF-14. An index of functional impairment in patients with cataract. Arch Ophthalmol, 112:630-8.

Steinberg EP, Tielsch JM, Schein OD, et al. 1994b. National study of cataract surgery outcomes. Variation in 4-month postoperative outcomes as reflected in multiple outcome measures. Ophthalmology, $101: 1131-41$
Wang JJ, Mitchell P, Smith W, et al. 1999. Impact of visual impairment on use of community support services by elderly persons: the Blue Mountains Eye Study. Invest Ophthalmol Vis Sci, 40:12-19.

Wang JJ, Mitchell P, Simpson JM, et al. 2001. Visual impairment, agerelated cataract and mortality. Arch Ophthalmol, 119:1186-90.

Williams RA, Brody BL, Thomas RG, et al. 1998. The psychosocial impact of macular degeneration. Arch Ophthalmol, 116:514-20.

[WHO] World Health Organization. 2001. International classification of functioning disability and health. Geneva, Switzerland, pp. 18-20. 